\title{
Influence of amino acids sequence on metal binding properties of selected pentapeptides - fluorescence and UV-Vis spectroscopy studies
}

\author{
Joanna Makowska, Dominik Kamrowski, Krzysztof Żamojć, Dariusz Wyrzykowski, Lech Chmurzyński \\ Department of General and Inorganic Chemistry, Faculty of Chemistry, University of Gdańsk, Wita Stwosza 63, Gdańsk, Poland
} Corresponding author: krzysztof.zamojc@ug.edu.pl

DOI: 10.31708/spi3.18/makdo.cns18

\section{Introduction}

Interactions between peptides and metal ions are the subject of constant investigations, as they are considered to be of great significance. For instance, it has been shown that several ions, e.g. Cu2+ and $\mathrm{Zn2}+$, are involved in the amyloid- $\beta$ peptide aggregation process, which presumably plays the main role in Alzheimer's disease (Nair, Perry, Smith, \& Reddy, 2010). From among all amino acids present in the $A B$ sequence, histidine and tyrosine side chains are proven to have a distinct affinity for $\mathrm{Cu} 2+$ and other metal cations (Murariu et al., 2018). The aim of our work was to investigate potential applications of fluorescence and UV-Vis spectroscopy for research into interactions between several metal cations (Mn2+, $\mathrm{Fe} 2+, \mathrm{Co} 2+$, $\mathrm{Ni2}+$, Cu2+ and $\mathrm{Zn2+)}$ and four selected peptides (EYHHQ, EHYHQ, EHHQY and KYHHE).

\section{Materials and Methods}

The peptides: EHHQY, EHYHQ, EYHHQ and KYHHE were synthesized using a procedure described previously (Makowska, Bagińska, Liwo, Chmurzyński, \& Scheraga, 2008). Their stock solutions $(0.1 \mathrm{mM})$ were prepared by dissolving proper amount of peptides in 5 mM MES buffer (pH 6.0). Inorganic salts: $\mathrm{Cu}(\mathrm{II}), \mathrm{Zn}(\mathrm{II})$, $\mathrm{Mn}(\mathrm{II}), \mathrm{Co}(\mathrm{II}), \mathrm{Ni}(\mathrm{II})$ nitrates and $\mathrm{Fe}(\mathrm{II})$ chloride were purchased from Sigma-Aldrich and dissolved in the 5 mM MES buffer ( $\mathrm{pH} \mathrm{6.0)}$ to concentration of $16 \mathrm{mM}$. All steady-state fluorescence measurements were performed at room temperature on a Cary Eclipse Varian spectrofluorometer. The excitation and emission wavelengths were set to $275 \mathrm{~nm}$ and $305 \mathrm{~nm}$, respectively. Absorption spectra essential to inner-filter corrections were recorded on a Perkin Elmer Lambda 650 UV-Vis spectrophotometer at room temperature.

\section{Results}

Fluorometric titrations were conducted for all 24 peptidemetal combinations. No significant changes in fluorescence intensity were observed in all samples containing Mn2+, $\mathrm{Fe} 2+, \mathrm{Co} 2+$ and $\mathrm{Zn2}+$ ions. Titrations of selected peptides against $\mathrm{Cu} 2+$ ions induced significant and rapid changes in fluorescence intensity, therefore it was possible to determine the stoichiometry
( 1 mole of $\mathrm{Cu} 2+$ per 2 moles of peptide in all cases), as exemplified in Fig. 1, and stability constants of obtained complexes (results not shown).

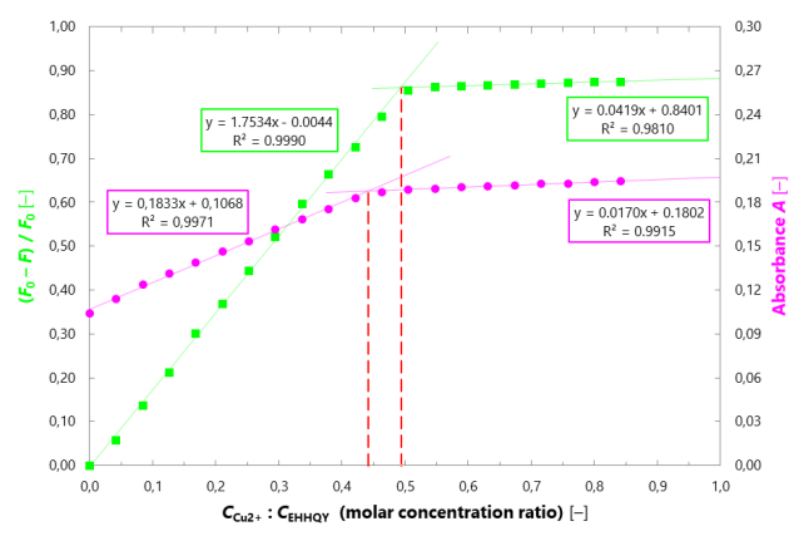

Fig. 1. The plot of (F0 - F)/F0 and absorbance (at $275 \mathrm{~nm})$ against the titrant to analyte (Cu2+ to EHHQY) molar concentration ratio. Line-line intersections represent the stoichiometry of the formed Cu2+-EHHQY complex.

Investigations of interactions between peptides and $\mathrm{Ni2}+$ ions provided surprising results. Fluorescence intensity of $E Y H H Q$ and $E H Y H Q$ peptides was not affected by adding further portions of $\mathrm{Ni2}+$ ions. Contrarily, EHHQY$\mathrm{Ni} 2+$ and KYHHE-Ni2+ interactions led to a slow but indisputable decrease of fluorescence intensity.

\section{Discussion}

The fluorometric titration is a useful method for monitoring Cu2+-peptide interactions. The stoichiometry $(1: 2)$ and stability constants of formed complexes were determined with satisfactory accuracy. However, this experiment is not applicable to study interactions between selected peptides and other chosen metal ions, namely $\mathrm{Mn} 2+, \mathrm{Fe} 2+, \mathrm{Co} 2+$ and $\mathrm{Zn} 2+$. Ni2+-peptide interactions will be investigated further. Described differences between properties of the selected peptides (EYHHQ, EHYHQ vs. EHHQY, KYHHE) have proven existence of a connection between a peptide sequence and its metal binding properties. It is probable that the Glu-His-His (and opposite) arrangement of amino acids is responsible for observed distinctions. However, with 
no doubt it needs further examinations. It was observed that $E Y H H Q$ and $E H Y H Q$ peptides interact exclusively and instantly with the Cu2+ ions (any interactions with other selected metals were insignificant when investigated by fluorescence spectroscopy). This fact might imply the application of EYHHQ and EHYHQ peptides as $\mathrm{Cu} 2+$ ions sensors. Our hypothesis requires subsequent measurements to be confirmed.

\section{Acknowledgments}

This work was financially supported by the Polish National Science Centre (NCN) under Grant No. 2016/23/D/ST4/01576.

\section{References}

Makowska, J., Bagińska, K., Liwo, A., Chmurzyński, L., \& Scheraga, H. A. (2008). Acidic-basic properties of three alanine-based peptides containing acidic and basic side chains: Comparison between theory and experiment. Biopolymers - Peptide Science Section, 90(5), 724-732. https://doi.org/10.1002/bip.21046

Murariu, M., Habasescu, L., Ciobanu, C.-I. I., Gradinaru, R. V., Pui, A., Drochioiu, G., \& Mangalagiu, I. (2018). Interaction of Amyloid $A \beta(9-16)$ Peptide Fragment with Metal Ions: CD, FT-IR, and Fluorescence Spectroscopic Studies. International Journal of Peptide Research and Therapeutics, 113. https://doi.org/10.1007/s10989-018-9738-1

Nair, N. G., Perry, G., Smith, M. A., \& Reddy, V. P. (2010). NMR studies of zinc, copper, and iron binding to histidine, the principal metal ion complexing site of amyloid- $\beta$ peptide. Journal of Alzheimer's Disease, 20(1), 57-66. https://doi.org/10.3233/JAD-2010-1346 